\title{
Public Speaking serta Teknik Ice Breaking dan MC Sebagai Upaya Pengajaran yang Menarik
}

\author{
Rudi Kristanto ${ }^{1}$, Sudarwanto ${ }^{2}$ Wahyuni Kurniawati ${ }^{3}$ \\ Institut Ilmu Sosial dan Manajemen STIAMI, Jakarta, Indonesia 1,2,3 \\ rudi.kristanto@stiami.ac.id,darwanto@stiami.ac.id,wahyuni@stiami.ac.id
}

\section{ARTICLE INFO}

Keywords

public speaking, ice

breaking,

master of ceremonies $(M C)$,

audience, Communication.
ABSTRACT

Methods of public speaking and ice breaking, master of ceremonies (MC), or "master of ceremonies" are very important to support activities that are often carried out in an institution or institutions, both governmental and non-governmental organizations in activity both formal or activity on formal at every activity event. Students often feel less touched by the teaching methods presented so there is a need for creativity in communication that has an impact on the effectiveness and is interesting in the teaching and learning process.

Public speaking, can improve expertise in academics and careers, improve communication skills in general. Public Speaking will develop and improve communication skills, improve speaking skills in front of an audience. The speaker is not born but is created. Ice-breaking can create conditions that are equal or equal to fellow trainees, eliminating gaps or boundaries between participants, so there are no differences so that similarities and opportunities for progress arise. The Master of Ceremonies MC was introduced by the SAPA method (Greetings and Greetings, Appreciation, Introductions, Attention and Event Description). This method is easy to remember and easy to memorize.

All the participants felt the benefits and said that the event was lacking in time. So it was felt that it was necessary to make similar activities aimed at providing soft skills to all audiences

\section{A. PENDAHULUAN}

Berkomunikasi atau menyampaikan sebuah materi tidaklah sesederahana seperti apa yang diharapakan, dibutuhkan pelatihan-pelatihan dan keterampilan serta pengetahuan yang memadai, sehingga pesan yang akan disampaikan mudah diserap oleh pendengar. Keterbatasan pemahaman dilapangan menunjukan terkadang membuat jenuh audiens dalam menyerap materi yang disampaikan. Kemampuan berbicara di muka umum (public speaking) sangat penting dikuasai oleh para pengajar baik para dosen-dosen ataupun guru-guru di sekolah.

Pengajaran yang yang menarik dewasa ini adalah ketika metode public speaking yang sampaikan kepada audiens mempunyai daya tarik tersendiri dan menjadi magnet perhatian. Teknik dan metode public speaking yang baik, serta pintar dikarenakan dapat mengatur irama dan intonansi serta dapat menarik audiens masuk ke tiap segmen materi yang disampaikan. Dan seorang pembicara dikatakan sukses dimuka umum ini apabila pendengar merasa puas terhadap materinya, serta kemudian merespon secara positif dari materi yang diterima dan disampaikan.

Metode ice breaking sangat baik dilakukan para pengajar baik para dosen-dosen ataupun guruguru karena berfungsi memecah kebosanan atupun kejenuhan serta kebekuan para audience yang hadir di kegiatan seperti workshop, seminar, outbond, pelatihan, kegiatan tersebut dapat dilakukan di dalam ruangan (indoor) ataupun diluar ruangan (outdoor).

Selain teknik berkomunikasi public speaking serta ice breaking, master of ceremonies (MC), atau "pembawa acara" sangat penting mendukung kegiatan kegiatan yang sering dilakukan di sebuah institusi ataupun lembaga-lembaga, master of ceremonies $(M C)$ sangat membantu sebuah institusi, 
lembaga atau badan, organisasi baik pemerintahan ataupun non pemerintahan didalam sebuah kegiatan baik formal ataupun kegiatan non formal untuk membawakan acara pada setiap event-event kegiatan.

\section{Masalah}

Masalah yang dihadapi oleh para dosen-dosen di Institut STIAMI adalah para mahasiswa sering merasa kurang tersentuh dengan metode pengajaran yang disampaikan sehingga perlu adanya kreativitas dalam komunikasi yang berdampak pada efektivitas dan menarik dalam proses pengajaran dan pembelajaran. Berdasarkan masalah tersebut, Metode public speaking serta ice breaking dan master of ceremonies $(M C)$ memberikan sentuhan sendiri dalam teknik pengajaran di kalangan mahasiswa, sehingga mahasiswa dapat lebih mudah memahami materi yang disampaikan baik secara verbal ataupun non verbal dalam proses pembelajaran.

\section{B. METODE PELAKSANAAN KEGIATAN}

Pelaksanaan dari kegiatan public speaking serta ice breaking, master of ceremonies $(M C)$ terdiri dari beberapa tahap sebagai berikut:

\section{Persiapan Kegiatan}

Persiapan yang dilakukan tim PkM Institut STIAMI adalah dengan melibatkan civitas akademika para dosen-dosen pengajar Tema "Public Speaking serta Ice Breaking dan MC" yang di adakan pada, Jumat, 22 Februari 2018.

Pemberitahuan serta komunikasi dilakukan melalui via telepon, whatsApp, infograhis kegiatan, dan pertemuan tatap muka. Persiapan dilakukan menyangkut waktu dan jadwal kegiatan, peserta kegiatan, isi konten pelatihan, metode dan pendekatan pelatihan, lokasi dan tempat kegiatan, ruangan serta konsumsi para peserta dan pembicara.

\section{Pelaksanaan Kegiatan}

Peserta kegiatan pelatihan dibagi dalam dua sesi dengan masing-masing terdiri dari 35 orang peserta. Sesi pertama di lakukan pada pukul, 08.30 WIB s.d 10.00 WIB, sedangkan sesi yang kedua pada puku, 10.05 WIB s.d 11.30 WIB, bertempat di kampus pusat, Jl. Pangkalan Asem Raya No. 55 Cempaka Putih, Jakarta Pusat 10530.

\section{Evaluasi Kegiatan}

Tim PkM Institut STIAMI membuat evaluasi kegiatan yang dilakukan terhadap efektivitas dan minat audiens dalam mengikuti kegiatan pelatihan, dengan memberikan angket - angket pertanyaan dan masukan-masukan dari audiens.

\section{HASIL DAN PEMBAHASAN}

Keberadaan dosen di universitas dan guru sebagai pengajar di sekolah sangatlah penting, keberadaan mereka di tengah-tengah, masyarakat, organisasi, kegiatan ilmiah tidak pernah lepas dunia seni berbicara di muka publik atau public speaking.

Kemampuan berbicara secara ilmiah ataupun non ilmiah menjadi motivasi tersendiri bagi audiens yang mendengararkan, hal ini adalah sangat wajar karena teknik tersebut meliputi kemampuan gestur tubuh sangat meyakinkan, intonasi berbicara yang tenang, pengetahuan yang dimiliki oleh si pembicara.

Keberadaan para pendidik guru dan dosen sangat diperhatikan oleh negara, hal tersebut tertuang dalam ketentuan undang-undang negara kita. Undang-Undang Republik Indonesia Nomor 14 Tahun 2005 Tentang Guru dan Dosen Pasal 1 menyebutkan :

1. Guru merupakan pendidik profesional dengan tugas utama untuk mendidik, mengajar, membimbing, mengarahkan, melatih, menilai, serta melakukan evaluasi peserta didik pada pendidikan anak usia dini jalur pendidikan formal, pendidikan dasar, dan pendidikan menengah. 
2. Dosen merupakan pendidik profesional dan ilmuwan dengan tugas utama untuk mentransformasikan, mengembangkan, serta menyebarluaskan ilmu pengetahuan, teknologi, dan seni melalui pendidikan, penelitian dan pengabdian kepada masyarakat.

Pelaksanaan kegiatan Public Speaking dan Teknik Ice Breaking dan MC ini dibagi dalam beberapa kegiatan sebagai berikut :

\section{Public Speaking}

Bedasarkan teori De Vito (2009), terdapat keuntungan dicapai seseorang mempelajari Public Speaking. Keuntunagnnya sebagai berikut:

a. Dapat meningkatkan keahlian dalam bidang akademik dan karir :

1. Dapat menerangkan konsep-konsep yang kompleks dengan jelas.

2. Meneliti berbagai persoalan secara luas

3. Mendukung argumentasi dengan semua persuasi yang berarti

4. Memahami motivasi manusia serta mampu menggunakan pandangannya dengan persuasi

5. Menghadirkan kemampuan yang dimiliki kepada orang lain dengan penuh kepercayaan dan keyakinan diri

b. Memperbaiki kemampuan berkomunikasi secara umum. Public Speaking akan mengembangkan dan memperbaiki kemampuan berkomunikasi seseorang secara umum, seperti

1. Mengembangkan gaya komunikasi secara efektif

2. Meningkatkan kemampuan diri dan harga diri

3. Menyesuaikan pesan yang disampaikan untuk pendengar yang spesifik

4. Mendengarkan dan menanggapi umpan balik

5. Mengembangkan daya tarik logika dan emosional

6. Mengembangkan serta mengkomunikasikan kecerdasan seseorang

7. Meningkatkan kemampuan untuk dapat menyampaikan kritik yang membangun

8. Memperbaiki ketrampilan mendengarkan dari orang lain

9. Mengorganisasikan penyampaian pesan secara jelas dan meyakinkan

c. Meningkatkan kemampuan berbicara di depan audiens. Pembicara bukan dilahirkan, namun diciptakan. Seseorang dapat menjadi pembicara melalui beberapa instruksi, membuka dengan pembicaraan yang berbeda dan pengalaman yang dipelajari sendiri sehingga menjadi lebih mampu, lebih percaya diri dan menjadi pembicara yang efektif, serta memiliki kemampuan dalam menyampaikan kritik.

Tahapan-tahapan public speaking yang di lakukan sebagai berikut :

1. Analisis Audiens

Dalam setiap segiatan yang dilakukan usahakan kenali para audiens, dari jenis kelamin, usia, pendidikan, kultur sosial dan budaya.

2. Sebuah Penarik Perhatian (Attention-Getter).

Buatlah sebuah kisah yang menarik seperti ketokohan, kepahlawan, ketauladanan yang membangkitkan motivasi atau joke joke yang lucu, sehingga suasana menjadi cair

3. Buatlah Tesis \& Inti Pembicaraan

Tentukan tujuan dari pembicaraan yang dimaksud, bagaimana audiens merespon materi yang disampaikan

4. Bahan-bahan Pendukung

Untuk mendukung dan melengkapi kegiatan tersebut siapkan dokumen dan dokumentasi. Dokumen yang dibutuhkan untuk bahan-bahan presentasi berupa statistik, kutipan, testimoni pakar, cerita, opini publik. 


\section{Tutup dengan Baik}

Kesimpulan dibuat dengan singkat jelas dan padat, usahakan ditutup dengan sebuah kesan yang diambil dari kutipan orang-orang ternama atau tokoh tokoh, dan buatlah kata motivasi yang membangun kepercayaan kepada audiens.

\section{Ice Breaking}

Selanjutnya ice breaking bisa diartikan sebagai usaha untuk memecahan atau mencairkan suasana yang kaku seperti es agar menjadi lebih nyaman mengalir dan santai. Hal ini bertujuan agar materi-materi yang disampaikan dapat diterima (Nida, 2011).

Tujuan dilaksanakan ice breaking adalah :

1. Menciptakan kondisi yang sejajar atau setara sesama peserta pelatihan.

2. Menghilangkan gap atau kesenjangan, batas antara peserta, sehingga tidak ada perbedaan , sehingga muncul persamaan dan kesempatan untuk maju.

Langkah - langkah persiapan sebelum ice breaking

a) Persiapan untuk permainan ice breaking

Kumpulkan semua jenis permainan yang menarik di dalam kegiatan yang akan dilakukan dan pilihlah permainan yang tidak mengandung unsur sara ataupun berbahaya dan unsur kerjasama serta waktu yang efektif.

b) Memulai permainan ice breaking

Minta secara sukarela kepada para peserta untuk mencoba permainan yang diarahkan kepada peserta sehingga mereka bisa memahami permainan tersebut, dan manfaatkan waktu secara komunikatif kepada peserta sehingga tercipta suasana yang baru dan menyenangkan.

\section{3. (MC) Master of Ceremonies}

Tujuan Master of Ceremonies MC adalah mengumumkan susunan acara dan memperkenalkan orang yang akan tampil mengisi acara, serta bertanggung jawab memastikan acara berlangsung lancar dan tepat waktu, serta meriah dan khidmat dari awal hingga akhir.

Menurut Wiyanto dan Astuti (2002:2) Pembawa Acara adalah orang pertama yang berbicara dalam suatu acara (Wiyanto dan Astuti, 2002:2). Sebagai pembawa acara, dia harus bisa menarik perhatian hadirin untuk segera merasa terlibat dalam pertemuan itu. Kalau upaya ini gagal, jalannya acara menjadi hambar, tidak berkesan dan mengecewakan.

Dalam pelatihan ini para peserta dikenalkan dengan metode SAPA DIA (Salam dan Sapa, Apresiasi, Perkenalan, Atensi dan Deskripsi Acara). Metode ini mudah diingat dan mudah untuk dihafalkan :

\section{a) Salam dan Sapa}

Salam dan sapa adalah hal yang penting disampaikan seorang MC sebagai kata pembuka dan signal kepada peserta, kesan pertama yang baik akan membuat perserta menjadi menarik untuk memperhatikan MC di depan.

\section{b) Apresiasi}

Apresiasi kepada peserta penting untuk di ucapkan, banyak mereka yang terlibat dan hadir di acara tersebut, apresiasi tersebut adalah penghargaan kepada para audiens dan element-elemant yang terlibat.

c) Perkenalan

Memperkenalkan diri adalah hal yang sering dilupakan oleh MC, para audiens akan sangat lebih dekat dengan MC karena lebih mengenal sosok MC yang memandu kegiatan yang dilakukan. 


\section{d) Atensi}

Ciptakan Atensi pada saat kita membuka kegiatan atau acara. Atensi adalah perhatian adalah sesi untuk menarik perhatian dari audiens agar fokus kepada acara yang sedang pandu. Peserta dapat diajak melakukan permainan-permainan, melakukan gerak, serta membuat atau meniriakan yel yel.

\section{e) Deskripsi Acara}

Pada tahapan ini MC memberikan gambaran singkat tentang acara kegiatan yang akan berlangsung, sehingga peserta mempunyai gambaran yang jelas tetntang kegiatan yang dilakukan.

Gambar 1. Kegiatan public speaking

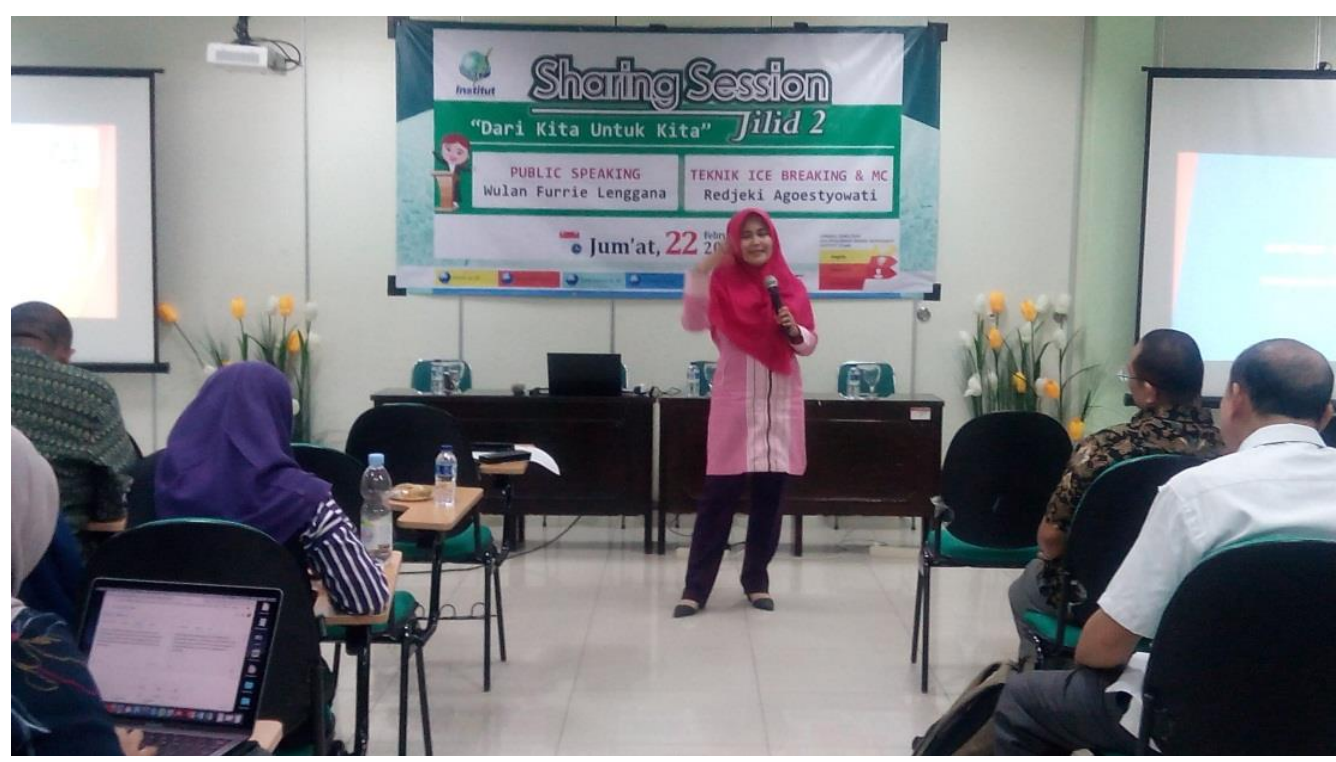

Gambar 2. Kegiatan ice breaking dan MC

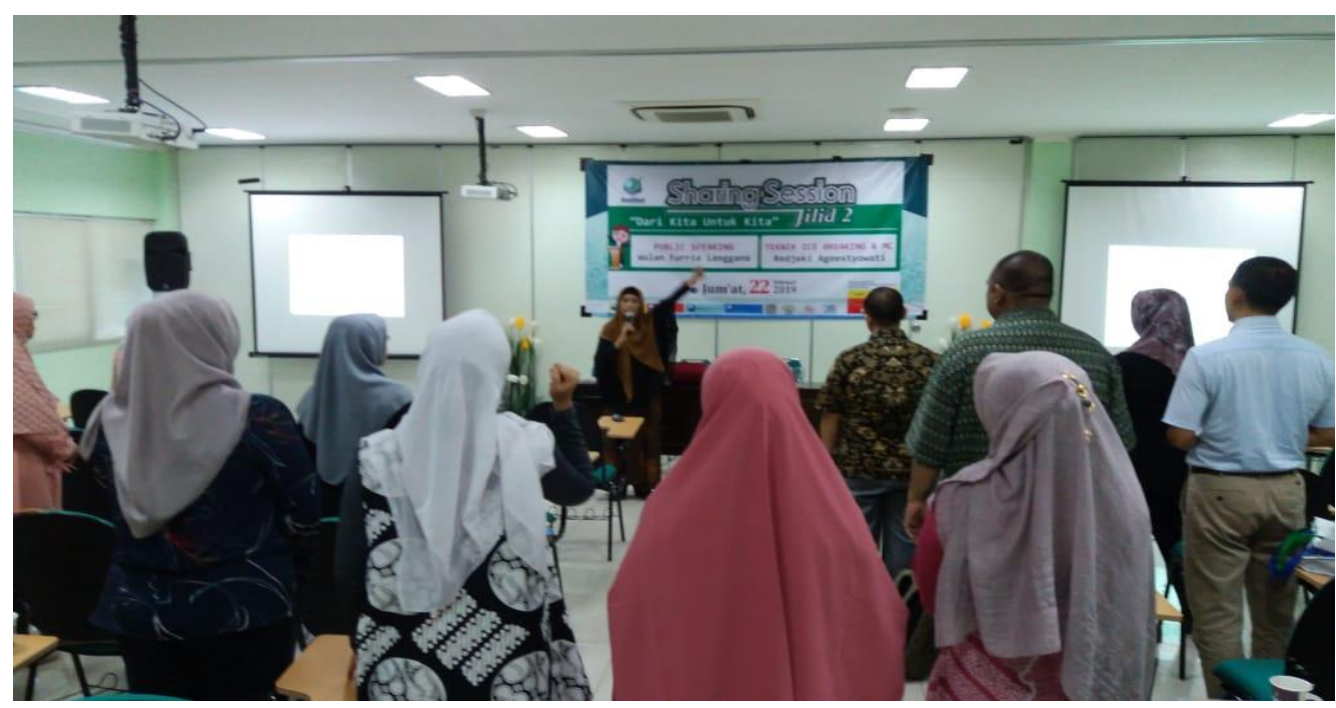


Gambar 3. Foto peserta kegiatan public speaking serta ice breaking dan MC

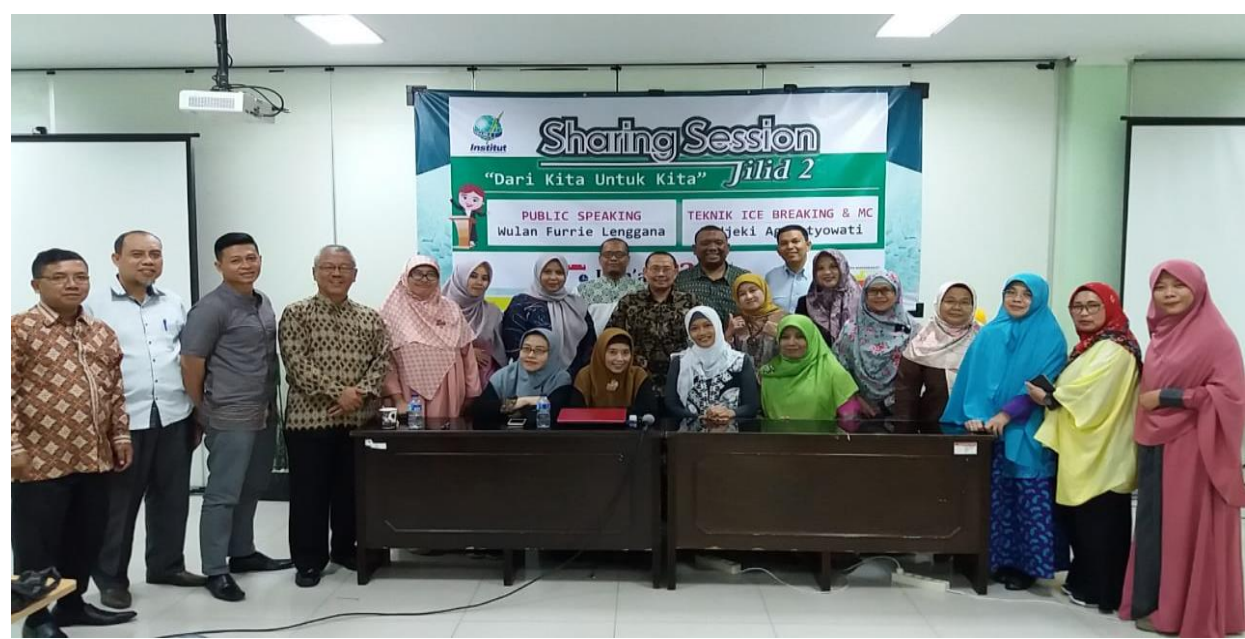

\section{KESIMPULAN DAN SARAN}

Kegiatan pelatihan public speaking ataupun ice breaking, master of ceremonies $(M C)$, di Institut STIAMI berjalan lancar sesuai dengan harapan dan diharapkan para peserta ke depan dapat mengaplikasikannya dalam pengajaran sehingga metode pengajaran menjadi lebih hidup, berwarna dan dapat memotivasi para mahasiswa. Audiens aktif mengajukan banyak pertanyaan-pertanyaan seputar kegiatan dan mendapat pencerahan dari pemateri yang berasala dari dosen akademisi dan praktisi yang sehari hari adalah sebagai profeosional di bidang public speaking ataupun ice breaking, master of ceremonies $(M C)$. Dari semua peserta merasakan manfaat dan menyampaikan bahwa acara ini waktunya kurang. Sehingga dirasakan hal tersebut perlu untuk dibuat kegiatan serupa yang bertujuan untuk memberikan soft skill kepada semua audiens.

\section{DAFTAR PUSTAKA}

De Vito, Joseph A. 2009. The Essential Elements of Public Speaking. USA:Pearson

Nida, 2011. "Varian Ice Breaker: Segarkan Aktivitas Pembelajaran". (http://komunikasi.um.ac.id, diakses 28 november 2014).

Wiyanto, Asul, dan Prima K Astuti. (2002). Terampil Membawa Acara. Jakarta: Grasindo

Hidajat, M.S. (2006). Public Speaking \& Teknik Presentasi. Yogyakarta: Graha Ilmu.

\section{Sumber lain :}

http://www.jdih.kemenkeu.go.id/fullText/2005/14TAHUN2005UU.HTM

https://belajarpublicspeaking.com/6-hal-persiapan-public-speaking

http://fauzinoerwenda.com/5-tahapan-spesial-bagi-mc-dalam-membuka-acara-tahapan-ketiga-yangseringkali-terlupakan/

https://id.wikipedia.org/wiki/Pembawa_acara

https://lppm.stiami.ac.id/wp/?page_id=584 